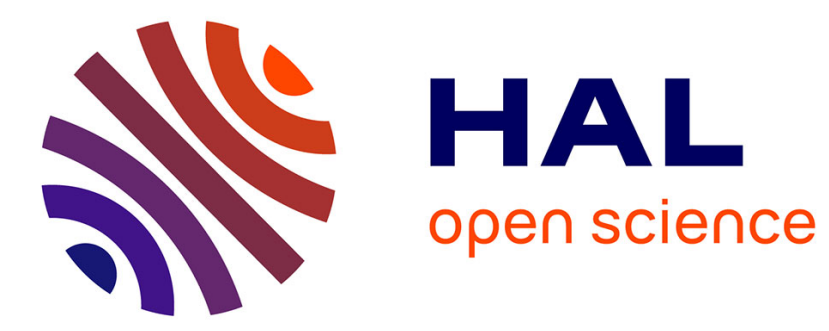

\title{
GRAIN BOUNDARY CHEMISTRY OF NiAl
}

P. Camus, I. Baker, J. Horton, M. Miller

\section{To cite this version:}

P. Camus, I. Baker, J. Horton, M. Miller. GRAIN BOUNDARY CHEMISTRY OF NiAl. Journal de Physique Colloques, 1988, 49 (C6), pp.C6-329-C6-333. 10.1051/jphyscol:1988657 . jpa-00228154

\section{HAL Id: jpa-00228154 https://hal.science/jpa-00228154}

Submitted on 1 Jan 1988

HAL is a multi-disciplinary open access archive for the deposit and dissemination of scientific research documents, whether they are published or not. The documents may come from teaching and research institutions in France or abroad, or from public or private research centers.
L'archive ouverte pluridisciplinaire HAL, est destinée au dépôt et à la diffusion de documents scientifiques de niveau recherche, publiés ou non, émanant des établissements d'enseignement et de recherche français ou étrangers, des laboratoires publics ou privés. 


\title{
GRAIN BOUNDARY CHEMISTRY OF NIAI
}

\author{
P.P. CAMUS, I. BAKER* , J.A. HORTON and M.K. MILLER \\ Metals and Ceramics Division, Oak Ridge National Laboratory. \\ Oak Ridge, TN 37831-6376, U.S.A. \\ * Thayer School of Engineering, Dartmouth College, Hanover, NH 03755. \\ U.S.A.
}

\begin{abstract}
Atom probe analyses performed at the grain boundaries in Ni-49 at. \% Al indicated a majority of regions that contained almost no aluminum and a few regions that indicated neither enrichment nor depletion of aluminum. The widths of the depleted zones were less than $0.5 \mathrm{~nm}$. It is proposed that this aluminum depleted zone could be a cause of the enhanced ductility and change in fracture mechanism that occurs in this intermetallic alloy as compared to NiAl alloys further from stoichiometry.
\end{abstract}

\section{INTRODUCTION}

Many transition metal aluminides are attractive materials for high temperature applications because of their oxidation resistance and high-temperature strength. However, these aluminides are typically brittle at low temperatures. The nickel aluminides $\mathrm{NiAl}$ and $\mathrm{Ni}_{3} \mathrm{Al}$ in particular have received considerable attention. $\mathrm{Ni}_{3} \mathrm{Al}$ is appealing because its. strength increases as a function of increasing temperature, although binary alloys exhibit limited ductility. ${ }^{[1]}$ The addition of more than -0.1 at. $\%$ boron to $\mathrm{Ni}_{3} \mathrm{Al}$ has been shown to markedly change the fracture behavior from intergranular to transgranular failure and to increase the ductility. ${ }^{[2]}$ These changes in mechanical properties have been attributed to improved accommodation of dislocations at grain boundaries. ${ }^{[3]}$ The effect of boron is to lead to a cosegregation of nickel to the grain boundary ${ }^{[4,5]}$ which can be interpreted as a disordering of the boundary region. NiAl alloys are also attractive for high temperature applications due to their low density and high melting temperature. ${ }^{[6-8]}$ These alloys are similarly brittle and investigations are in progress to understand their deformation behavior, with particular reference to their grain boundary chemistry and structure.

NiAl has a $\mathrm{B} 2(\mathrm{CsCl})$ crystal structure that is fully ordered up to its congruent melting temperature of $1911 \mathrm{~K}$ $\left(1638^{\circ} \mathrm{C}\right) .[9]$ The $\mathrm{B} 2$ phase field has a wide range of aluminum solubility below $873 \mathrm{~K}\left(600^{\circ} \mathrm{C}\right)$ from $40-55$ at. \% aluminum. Room temperature fabrication problems arise because of the limited ductility of the material at low temperatures. In this material, dislocation motion occurs primarily on the $\{100\}<001>$ slip systems, which provides only three independent slip systems. ${ }^{[10]}$ Therefore only a limited general plasticity is possible. ${ }^{[11]}$ In contrast to $\mathrm{Ni}_{3} \mathrm{Al}$, interstitial element additions such as boron have been shown to have little effect on ductility. 12$]$ Substitutional additions such as titanium, iron, molybdenum, and niobium also have been shown to have little effect upon ductility and fracture behavior. ${ }^{[6,7]}$ The mechanical properties of NiAl alloys, however, are sensitive to deviations from stoichiometry. ${ }^{(12-14]}$ Hardness measurements show a minimum near the stoichiometric composition. ${ }^{[15]}$ Near-stoichiometric specimens also show the lowest yield stress and the highest ductility throughout the temperature range $200-1000 \mathrm{~K} .^{[14]}$ During fracture tests, severe deformation is observed at grain boundaries which leads to crack formation and subsequent fracture. ${ }^{[11]}$ At low temperatures, the fracture mode for stoichiometric NiAl is intergranular failure, whereas non-stoichiometric materials exhibit predominantly transgranular cleavage. ${ }^{[16]}$ A change in local order at the boundary was predicted to modify the dislocationboundary interactions and ultimately the fracture behavior of this material. ${ }^{[17]}$

The grain size of $\mathrm{NiAl}$ has also been shown to influence fracture behavior.[18] Coarse-grained materials have a lower stress for crack propagation than for crack nucleation and they fracture at low strains. In contrast, finegrained materials need a larger stress for crack propagation than for crack nucleation and must first work harden, leading to greater measured ductility. For example, at $673 \mathrm{~K}\left(400^{\circ} \mathrm{C}\right)$, Ni-49 at. \% Al exhibits ductility that is essentially constant at $2-3 \%$ for grain sizes greater than $20 \mu \mathrm{m}$ diameter. However, for the same material with a grain size under $10 \mu \mathrm{m}$ diameter, the ductility increases to greater than $40 \%$. ${ }^{[8]}$

The structure of grain boundaries and their interactions with dislocations may affect the ductility and fracture behavior of NiAl alloys. The principal modification to the mechanical properties appears through the variation of the alloy stoichiometry. In this APFIM/TEM study, the grain boundary composition was investigated for a slightly nickel-rich NiAl alloy. 


\section{EXPERIMENTAL PROCEDURE}

A binary $\mathrm{Ni}-49$ at. \% $\mathrm{Al}$ alloy with a low level of impurities was triply extruded and recrystallized at $973 \mathrm{~K}$ $\left(700^{\circ} \mathrm{C}\right)$ to produce material with a grain size less than $5 \mu \mathrm{m}$ diameter. This procedure is described in detail elsewhere. ${ }^{[19]}$ Field-ion microscopy (FIM) specimens were fabricated by standard metallographic procedures. Specimens were previewed in a JEOL $100 \mathrm{C}$ transmission electron microscope (TEM) to pre-select specimens with a grain boundary in the apex region. Atom probe analyses were conducted with a specimen temperature of $45 \mathrm{~K}$ and a pulse ratio of 15 to $20 \%$. Multiple compositional profiles were obtained across each boundary to check the reproducibility of the results.

\section{RESULTS AND DISCUSSION}

The $\langle 100\rangle$ planes in stoichiometric NiAl consist of alternating pure-nickel and pure-aluminum atomic planes. The corresponding image in the FIM consists of alternating brightly-imaging and darkly-imaging planes, as shown in Fig. 1. Atom probe analyses revealed that the brightly-imaging planes consisted of nickel and the dimly-imaging planes consisted of aluminum. The observed contrast of the nickel planes differs from that observed in the $\mathrm{Ni}_{3} \mathrm{Al}$ alloy where the nickel planes image dimly and the mixed nickel-plus-aluminum planes image brightly. ${ }^{[20]}$

Grain boundaries were observed in the specimen apex by TEM and FIM, Fig. 2. TEM images obtained before and after atom probe analysis showed a $6^{\circ}$ angle between the boundary plane and the specimen axis, Fig. 2(a) and (b). A FIM image recorded at best-image-voltage is shown in Fig. 2(c). To enhance the visibility of grain boundaries, rapid evaporation was performed on specimens during photographic exposure. A micrograph obtained during the evaporation of approximately 5 atomic planes is shown in Fig. 2(d). These micrographs indicate that the grain boundary is not always planar. Atom probe analyses performed on this boundary usually indicated a depletion of aluminum at the boundary, although approximately $1 / 3$ of the analyses gave no indication of a composition change at the boundary. A representative composition profile across a depleted region of a boundary is shown in Fig. 3. The average composition in each grain was the nominal alloy composition of $49.2 \pm 0.5$ at. $\%$ aluminum whereas the aluminum content at the boundary dropped to approximately 38 at. \% aluminum.

A second boundary was found that possessed a $68^{\circ}$ angle between the boundary plane and the specimen axis, Fig. 4. The misorientation between the grains of a rotation of approximately $20^{\circ}$ about a common $\langle 110\rangle$ was measured from the FIM micrographs by the technique described by Bowkett and Smith.[21] This orientation corresponds to a coincidence site lattice designation of E33a. Atom probe analyses performed on this boundary usually indicated a region depleted in aluminum, although approximately $1 / 3$ of the analyses gave no indication of a composition change at the boundary. A composition profile across this boundary is shown in Fig. 5 . This profile illustrates the nominal composition in the grains and the depletion of aluminum at the boundary to approximately 38 at. \% aluminum.

The width of the depleted zone for both boundaries was estimated from the composition profiles as approximately $0.5 \mathrm{~nm}$. Other compositional measurements of depleted zones obtained from different positions on the same boundaries are summarized in Table 1. Composition measurements of the depleted regions were consistent along the same boundary and between boundaries. It should be noted that the measured compositions are averages over the probed volume, typically $2-3 \mathrm{~nm}$ in diameter. Because the depleted region was less than $0.5 \mathrm{~nm}$ wide and the probe diameter was larger, contributions to the measured compositions were obtained from both matrix and grain boundary regions and indicate a misleadingly high composition. Therefore, the composition of the grain boundary region was calculated by a technique that takes into account the areal fraction of the two regions. ${ }^{22]}$ This semi-quantitative estimate, assuming a $0.5 \mathrm{~nm}$ thick boundary region, indicated that the actual grain boundary composition may be almost pure nickel.

As is well known from the behavior of non-stoichiometric B2 NiAl alloys, nickel will occupy aluminum sites, but constitutional nickel-site vacancies are preferred to aluminum occupying nickel sites. [23] Thus, nickel-nickel nearest neighbors occur but aluminum-aluminum nearest neighbors do not. It seems likely, therefore, that, as observed in this work, either near-stoichiometric or nickel-rich regions, but not aluminum-rich regions, would form at grain boundaries. Furthermore, for non-planar boundaries, near-stoichiometric and nickel-rich regions could both exist along the same boundary, leading to the observed variation in local composition. Since a large proportion of nickel-rich regions were detected, local structures with nickel-nickel nearest neighbors appear preferable. Even without considering nearest-neighbor preferences, nickel-rich grain boundary regions could be predicted on the basis of the "smaller" nickel atoms allowing a higher atomic packing.

The aluminum depletion at the boundaries observed in this study possibly affects the mechanical properties of the grain boundary regions by a change in the dislocation-boundary interactions or by modifying the boundary structure. If the dislocation motion is controlled by compositional changes at the boundaries, the presence of a nearly pure nickel region could soften the boundaries sufficiently to permit greater ductility. These effects should be small due to the small width of the depleted zone. The enrichment of nickel at the boundaries could also modify the atomic structure of grain boundaries and increase their cohesive strength either through the increased packing efficiency or through the avoidance of the apparently unfavorable aluminum-aluminum bonds. In all cases, the enrichment of the nickel content at the boundaries apparently increases the grain boundary strength and thereby modifies the fracture behavior. 


\section{CONCLUSIONS}

Field-ion microscopy revealed that grain boundaries in Ni-49 at. \% Al are not necessarily planar. A majority of atom probe analyses of grain boundaries showed regions that contained almost no aluminum and a few regions that indicated neither enrichment nor depletion of aluminum. The thickness of these regions was estimated to be less than approximately $0.5 \mathrm{~nm}$. These depleted zones may be a reason for the increased ductility and change of fracture behavior in this NiAl alloy as compared to NiAl further from stoichiometry.

\section{REFERENCES}

1. P. H. Thorton, R. G. Davis, and T. L. Johnson, Metall. Trans., 1 (1970) 207

2. C. T. Liu, C. L. White, and J. A. Horton, Acta Metall., 33 (1985) 213

3. E. M. Schulson, T. P. Weihs, I. Baker, H. J. Frost, and J. A. Horton, Acta Metall., 34 (1986) 1395

4. D. D. Sieloff, S. S. Brenner, and M. G. Burke, "High-Temperature Intermetallic Alloys II", MRS Symp. Proc. Vol. 81, N. S. Stoloff, C. C. Koch, C. T. Liu, and O. Izumi eds. (MRS Publ., Pittsburgh, 1987) 87

5. I. Baker, E. M. Schulson, and J. R. Michael, Phil. Mag. B, 57 (1988) 379

6. K. Vedula, V. Pathare, I. Aslanidis, and R. H. Titran, "High-Temperature Intermetallic Alloys", MRS Symp. Proc. Vol. 39, C. C. Koch, C. T. Liu, and N. S. Stoloff eds. (MRS Publ., Pittsburgh, 1985) 411

7. J. R. Stephens, "High-Temperature Intermetallic Alloys", MRS Symp: Proc. Vol. 39, C. C. Koch, C. T. Liu, and N. S. Stoloff eds. (MRS Publ., Pittsburgh, 1985) 382

8. K. Vedula and J. R. Stephens, "High-Temperature Intermetallic Alloys II", MRS Symp. Proc. Vol. 81, N. S. Stoloff, C. C. Koch, C. T. Liu, and O. Izumi eds. (MRS Publ., Pittsburgh, 1987) 381

9. M. Hansen, "Constitution of Binary Alloys", (McGraw-Hill, NY, 1958) 118

10. G. W. Groves and A. Kelly, Phil. Mag., 8 (1963) 877

11. A. Ball and R. E. Smallman, Acta Metall., 14 (1966) 1349

12. R. B. Graham, M. E. Thesis, Dartmouth College, 1985

13. R. R. Vandervoort, A. K. Mukherjee, and J. E. Dorn, Trans. ASM, 59 (1966) 930

14. R. T. Pascoe and C. W. A. Newey, Metal Science Jnl., $\underline{2}$ (1968) 138

15. J. H. Westbrook, J. Electrochem. Soc., 103 (1956) 54

16. D. J. Gaydosh and M. A. Crimp, "High-Temperature Intermetallic Alloys", MRS Symp. Proc. Vol. 39, C. C. Koch, C. T. Liu, and N. S. Stoloff eds. (MRS Publ., Pittsburgh, 1985) 429

17. A. G. Rozner and R. J. Wasilewski, J. Inst. Metals, 24 (1966) 169

18. E. M. Schulson and D. R. Barker, Scripta Metall., 17 (1983) 519

19. I. Baker and E. M. Schulson, Metall. Trans. A, 15A (1984) 1129

20. J. A. Horton and M. K. Miller, J. de Phys., $47-\mathrm{C}_{2}$ (1986) 209

21. K. M. Bowkett and D. A. Smith, "Field Ion Microscopy", (North Holland, Amsterdam, 1970) 143

22. R. Herschitz and D. N. Seidman, Scripta Metall., 16 (1982) 849

23. A. J. Bradley and A. Taylor, Proc. Roy. Soc., A159 (1937) 56

\section{TABLE 1}

Apparent Aluminum Content of Grain Boundaries

\begin{tabular}{cccc} 
Specimen & Average & Specimen & Average \\
\cline { 5 - 5 } 1a & $40.6 \pm 1.3$ & $2 \mathrm{a}$ & $40.6 \pm 2.6$ \\
1b & $38.5 \pm 2.0$ & $2 \mathrm{~b}$ & $41.3 \pm 2.0$ \\
1c & $34.9 \pm 2.7$ & $2 \mathrm{c}$ & $41.1 \pm 1.5$ \\
& & $2 \mathrm{~d}$ & $39.8 \pm 2.6$ \\
mean & $39.4 \pm 1.0$ & mean & $40.9 \pm 1.0$
\end{tabular}

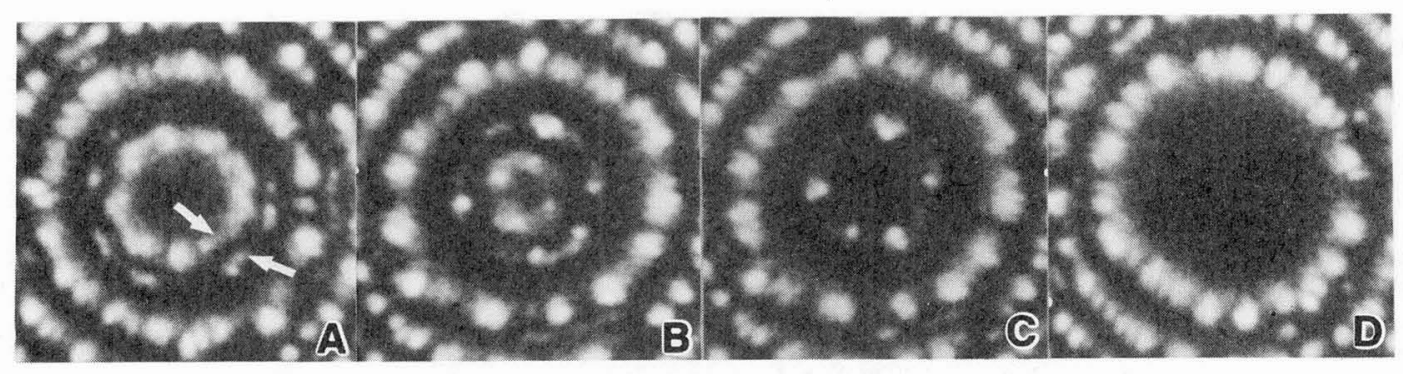

Fig. 1. A sequence of FIM images taken after field evaporation of a $<100>$ superlattice pole in B2-ordered NiAl material. Note the alternately brightly-imaging nickel planes and the dimly-imaging aluminum planes. 
Fig. 2. Complementary TEM and FIM images of a grain boundary in the same specimen. TEM micrographs obtained (a) before and (b) after atom probe analyses show a $6^{\circ}$ angle between the specimen axis and the grain boundary plane. The position of the grain boundary is less obvious in the field-ion image obtained at bestimage-voltage, (c), than in the image obtained while the specimen was evaporating, (d).

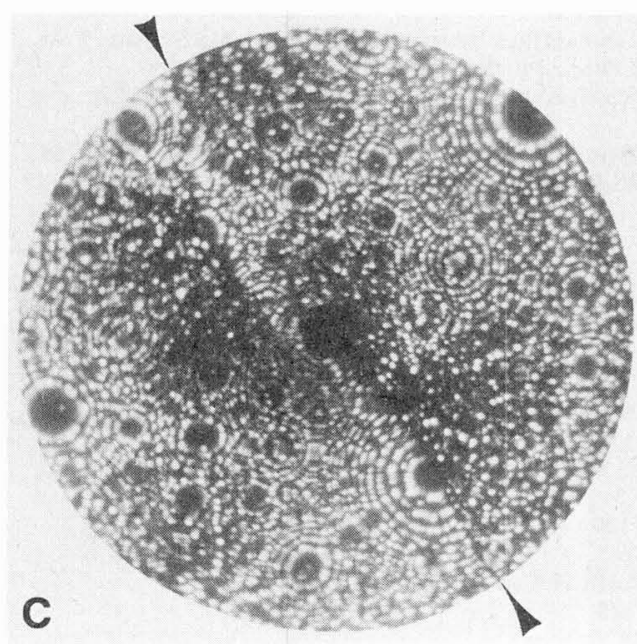

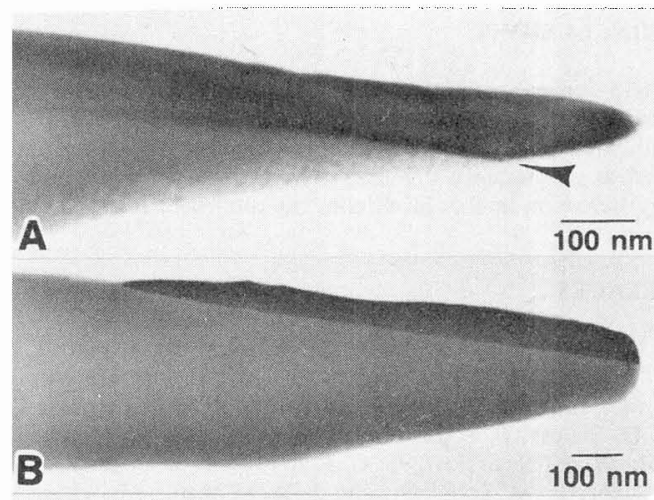

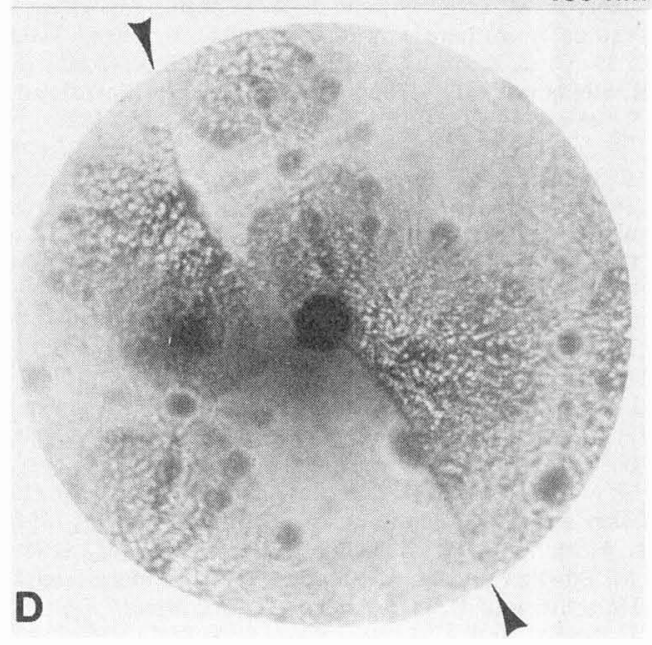

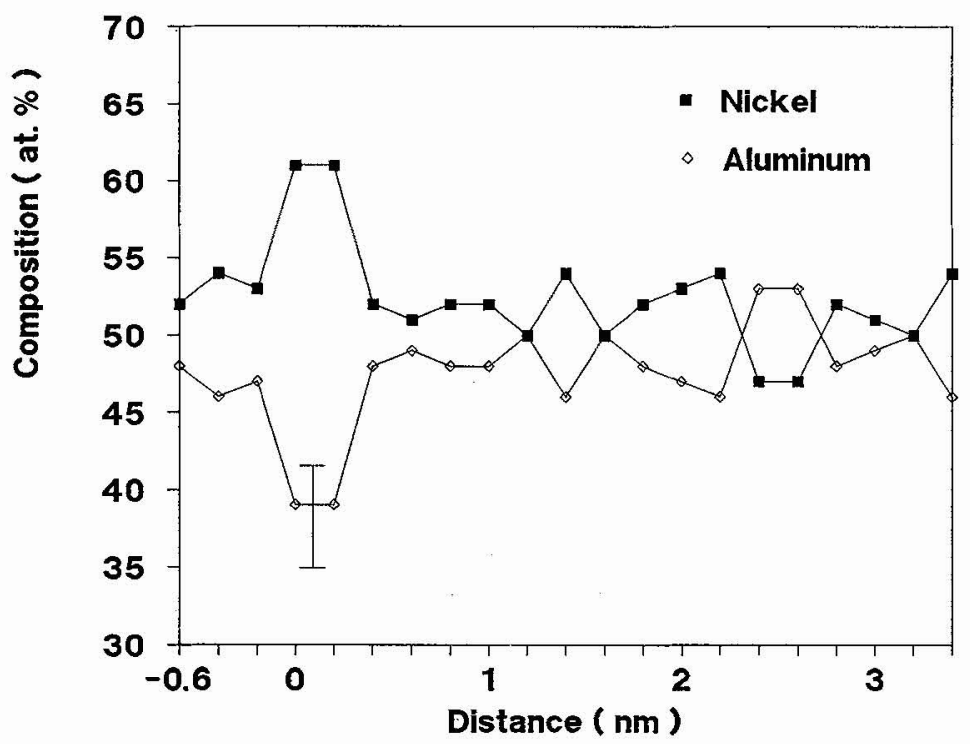

Fig. 3. Atom probe analysis of composition versus distance through the grain boundary obtained from the grain boundary shown in Fig. 2. Note the narrow aluminum-depleted region at the boundary. 


\section{ACKNOWLEDGEMENTS}

This research was supported by the Division of Materials Sciences, U.S. Department of Energy, under contract DE-AC05-84OR21400 with Martin Marietta Energy Systems, Inc., through the SHaRE program under contract number DE-AC05-76ORO0033 with Oak Ridge Associated Universities, and through grant number DE-FG02-87ER45311 to Dartmouth College. PPC acknowledges an appointment to the Postgraduate Research Training program administered by Oak Ridge Associated Universities. Special thanks to Dr. J. Bentley for helpful discussions.
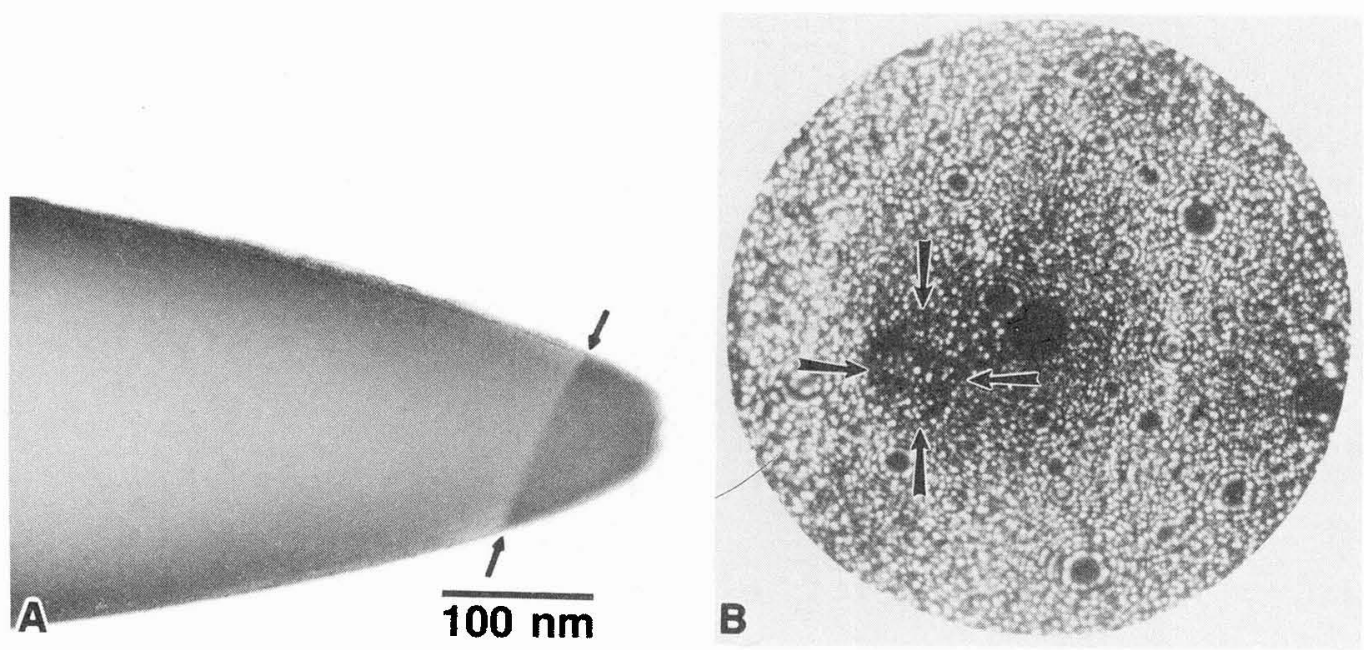

Fig. 4. Complementary TEM (a) and FIM (b) images of the same grain boundary. The TEM image indicates a $68^{\circ}$ angle between the specimen axis and the grain boundary plane. The misorientation between the grains was measured as a rotation of approximately $20^{\circ}$ about a common $\langle 110\rangle$. This corresponds to a coincident site lattice of $\Sigma 33 \mathrm{a}$.

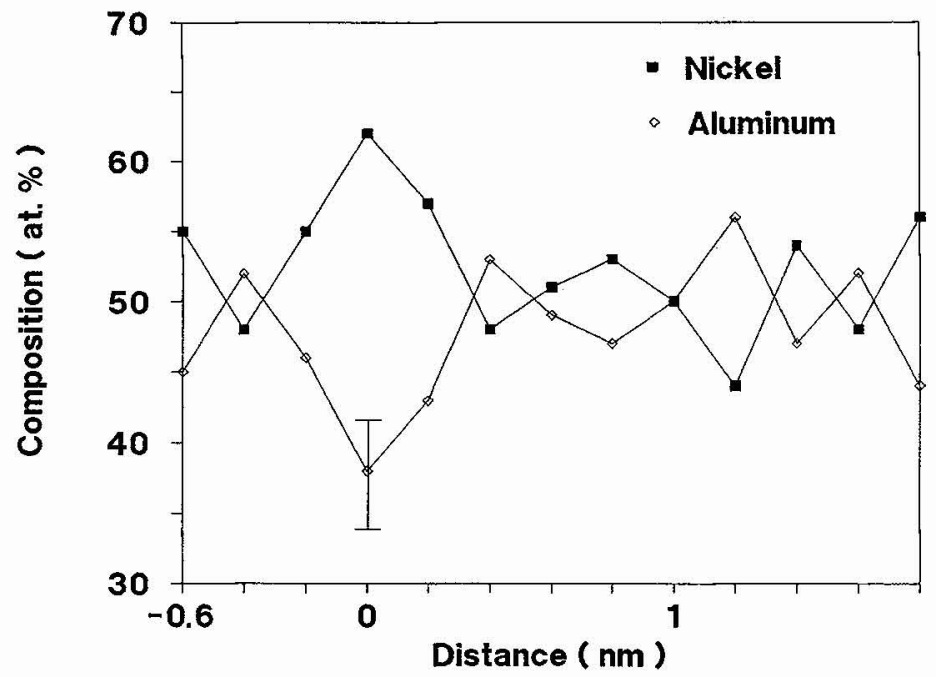

Fig. 5. Atom probe analysis of composition versus distance through the grain boundary obtained from the grain boundary shown in Fig. 4. Note the narrow aluminum-depleted region at the boundary. 